\title{
Desenvolvimento, desastres e emergências em saúde pública
}

\author{
Carlos Machado de Freitas', Simone Santos Oliveira1, Christovam Barcellos²
}

DOI: 10.1590/0103-11042020E200

EM ABRIL DE 2019, COMPLETANDO TRÊS MESES APÓS O DESASTRE provocado pela Vale, que atingiu Brumadinho com centenas de óbitos e afetou dezenas de outros municípios com a lama de rejeitos e seus contaminantes ao longo do Rio Paraopeba, começamos a preparar este número especial da revista 'Saúde em Debate', tendo como tema: Desenvolvimento, Desastres e Emergências em Saúde Pública. Nosso objetivo inicial foi combinar em um mesmo número a pesquisa acadêmica e o debate público sobre diferentes tipos de desastres e as emergências em saúde, incluindo a emergência climática. Embora interconectados, esses eventos e processos costumam ser abordados de modo distintos, por diferentes tradições científicas e organizações da sociedade. Ao mesmo tempo, ainda que constituam expressões dos processos de desenvolvimento social e econômico, nos níveis global, nacional, regional e local, são muitas vezes tratados como se fossem somente o resultado das falhas tecnológicas ou de eventos e processos da natureza.

Naquele mesmo ano, a partir do final de agosto, o Brasil foi surpreendido pelos primeiros locais atingidos com manchas de petróleo cru nas praias, afetando principalmente o litoral do Nordeste, chegando até aos litorais do Espírito Santo e do Rio de Janeiro, atingindo mais de 2,5 mil quilômetros de praias e constituindo um dos maiores desastres desse tipo em termos de extensão territorial.

Ainda em dezembro de 2019, tivemos a identificação de uma nova doença, a Covid-19, que viria a ser declarada uma pandemia global em 11 de março de 2020. De lá até hoje, o País se converteu em um dos epicentros da pandemia dessa doença, figurando entre os países com maior número de casos e óbitos.

No desastre da Região Serrana, em 2011, considerado um dos mais graves em termos de óbitos imediatos, foram registrados oficialmente 918 óbitos. No desastre provocado pela Vale em Brumadinho, em 2019, considerado um dos mais graves em barragens de mineração, foram registrados oficialmente 270 óbitos. No dia 19 de maio deste ano, ultrapassamos, pela primeira vez, a marca de mais de mil óbitos registrados em um único dia durante a pandemia de Covid19. Do primeiro óbito por essa doença, em 17 de março, até o dia 18 de maio, foram 16.792 óbitos, com uma média de 263 óbitos por dia, ou seja, um desastre da Vale em Brumadinho por dia em cerca de dois meses. Do dia 19 de maio até o dia 20 de julho, foram registrados 62.149 óbitos, com uma média de 986 óbitos por dia, ou seja, um desastre da Região Serrana por dia.

O levantamento desses números é relevante para que não se naturalizem os impactos desses eventos, em que o número de vidas perdidas é apenas um dos indicadores. É importante também para nos ajudar a refletir por qual razão o mesmo país que hoje é um dos epicentros da pandemia por Covid-19 também registrou os mais críticos desastres em barragens
1 Fundação Oswaldo Cruz (Fiocruz), Escola Nacional de Saúde Pública Sergio Arouca (Ensp) - Rio de Janeiro (RJ) - Brasil. caco.de.freitas@gmail.com

2 Fundação Oswaldo Cruz (Fiocruz), Instituto de Comunicação e Informação Científica e Tecnológica em Saúde (lcict) - Rio de Janeiro (RJ), Brasil. 
de mineração, um dos mais graves envolvendo chuvas fortes e deslizamentos de terra, um dos maiores em extensão litorânea e territorial envolvendo derrame de petróleo cru. Desastres, epidemias e pandemias não existem em um vazio; suas causas, consequências e capacidades de respostas sociais, incluindo as relacionadas aos sistemas de saúde, constituem a concretização dos processos de desenvolvimento social e econômico que produzem também vulnerabilidades e riscos ${ }^{1,2}$.

Os artigos publicados neste número abordam diversos aspectos relacionados com compreensão e estratégias de redução de riscos de desastres e emergências em saúde pública. Esperamos que sua leitura contribua para fortalecer o projeto de país que está expresso nos objetivos de nossa Constituição Federal de 1988, que são o de construir uma sociedade livre, justa e solidária, em que o desenvolvimento nacional esteja acoplado à erradicação da pobreza e da marginalização, orientado para a redução das desigualdades sociais e regionais. É como parte desse projeto de nação que se insere a saúde coletiva e que nasce o Sistema Único de Saúde, com seus princípios de universalidade, equidade e integralidade.

\section{Colaboradores}

Freitas CM (0000-0001-6626-9908)*, Oliveira SS (0000-0002-1477-749X)* e Barcelos C (0000-0002-1161-2753)* contribuíram igualmente para a elaboração do manuscrito.

\section{Referências} and Contributor ID).
1. Blaikie P, Cannon T, Davis I, et al. At Risk: Natural Hazards, People's Vulnerability and Disasters. London: Routledge; 1994.
2. Garrett L. A próxima peste: as doenças de um mundo em desequilíbrio. Rio de Janeiro: Nova Fronteira; 1995. 